\title{
THE HEAT FLOW FROM THE CONTINENTS
}

\author{
Henry N. Pollack
}

Department of Geological Sciences, University of Michigan, Ann Arbor, Michigan 48109

\section{INTRODUCTION}

The terrestrial heat flow is defined as the quantity of heat escaping per unit time from the Earth's interior across each unit area of the Earth's solid surface. The quantity varies from place to place over the surface of the Earth, as well as with time throughout Earth history. The total heat being lost from the Earth at a given time is the integral of the heat flow taken over the entire surface of earth. The heat flow from the continents is therefore but a part of the larger picture of global heat loss, indeed the lesser part when compared to the heat loss through the floor of the ocean basins. (Pollack 1980, Sclater et al 1980, Davies 1980). This is so not only because of the lesser continental area, but also because of the generally smaller heat flow found on the continents than in the ocean basins. Thus, a full discussion of the thermal regime of the Earth and the mechanisms by which it exhausts heat from the interior must center on the heat loss through the oceans, a topic which lies beyond the scope of this review. Nonetheless, because of the geological antiquity of at least some of their constituent terranes, the continents provide the only direct evidence about the thermal, tectonic, and petrologic processes of the Earth at times before the birth of any of the modern ocean basins some two hundred million years ago. Because inferences about earlier times are drawn wholly from materials now preserved in continents, one must be cautious not to overgeneralize about global tectonothermal processes from observations confined to continents.

\section{MEASUREMENT OF CONTINENTAL HEAT FLOW}

The heat flow through the continental crust in all but a few regions is largely by conduction, and can be represented by Fourier's law $\mathbf{q}=-K \operatorname{grad} \mathbf{T}$, 
where $\mathbf{q}$ is the heat flux vector, $K$ is the thermal conductivity of the material through which the heat is being conducted, and grad $T$ is the local temperature gradient. In practice, the determination of the heat flow comprises separate measurements of the temperature gradient and thermal conductivity. A useful general review and discussion of field and laboratory equipment and methods is given by Beck (1965).

Temperature gradients for heat flow determinations derive principally from measurements in boreholes, most of which have been drilled for other purposes, such as exploration for economic minerals, petroleum, and water, or engineering site evaluation for construction projects; a few boreholes have been drilled specifically for heat flow measurements. Boreholes drilled for economic minerals typically range from 50 to 300 meters, with occasional deeper holes. However, few satisfactory temperature measurements iemerge from the upper 50 meters of most boreholes, principally because of temperature disturbances associated with circulating groundwater. Occasionally, as in karst terranes, such disturbances can extend to a kilometer or more in depth, and render futile the attempt to measure a local temperature gradient. Conversely, in massive sparsely jointed crystalline bodies, in which circulation is inhibited, or in certain arid terranes where there is little water to circulate, satisfactory gradients can be determined within a few tens of meters of the surface. Temperature measurements in mineral exploration boreholes are usually taken as continuous logs or at depth intervals of a few meters.

Boreholes drilled for municipal or domestic water supplies are seldom deeper than 200 meters, are usually sited in aquifers, and frequently are of little use for geothermal investigations. Unsuccessful or abandoned water boreholes sometimes provide satisfactory temperature observations, particularly when several are clustered together so that a measure of redundancy is obtained.

Temperatures in shallow boreholes are perturbed to varying degree by the irregularities of the local topography and of the surface temperature distribution. Vegetative patterns, soil moisture, slope orientation, sun angle, and many other parameters influence the surface temperature distribution significantly (Blackwell et al 1980). Boreholes to depths less than or on the order of magnitude of the local relief require corrections to the observed temperature, in order to estimate the true geothermal gradient that would exist in the absence of topography and surficial temperature variations.

Boreholes drilled for petroleum are generally much deeper than mineral exploration or water bores, with depths of a few to several kilometers not uncommon. Temperature measurements in such boreholes are usually carried out by commercial service companies in conjunction with the taking of the common borehole logs. Only occasionally are temperatures logged continuously; more commonly spottemperatures are obtained at the bottom of the 
hole from time to time as drilling progresses. The rock at the bottom of the hole is in that segment of the borehole most recently excavated by the drill bit, and therefore least disturbed by the drilling process. However, "bottom hole temperatures" are not measured immediately after the drill reaches a given depth, but typically are taken after a period of circulating and flushing of the drilling fluid and extraction of the drill rods from the hole, procedures that may take a day or more and that may lead to bottom hole temperatures significantly different from the virgin rock temperature. These few bottom hole temperatures at different depths, when corrected for the drilling disturbance, enable an estimate of the mean geothermal gradient over the total depth of the hole, but ordinarily do not provide enough detail to resolve variation in the temperature gradient that may derive from lithologic variation with depth.

A temperature gradient can also be established from measurements at various levels in an underground mine. Commonly the observations are made in horizontal boreholes outward from the walls of drifts. A temperature disturbance propagates into the wall rock following the opening of the drift and the commencement of cooling ventilation. The distance into the wall rock that the perturbation propagates is dependent on how long the drift has been opened; even after several decades virgin rock temperatures can be found only a few tens of meters away from the wall. The temperatures so obtained at different levels unfortunately are seldom vertically beneath one another, and commonly temperatures obtained from different drifts at the same level show significant differences, particularly when the mine is not deep and topographic effects perturb the subsurface temperature field. Thus to infer a "true" vertical gradient, considerable massaging of the observations is necessary (Blackwell et al 1980, Henry 1981), and a greater uncertainty in the resulting value must be recognized.

Heat flow measurements have also been undertaken in lakes, utilizing marine techniques (Von Herzen \& Vacquier 1967, Sclater et al 1970, Degens et al 1971). Five to ten meter probes, with temperature sensors arrayed over the length, are allowed to plunge into the soft sediment on the lake bottom. Because saturated uncompacted sediment is a relatively poor conductor, easily measureable temperature differences exist over the probe length, and thus a temperature gradient is determined. However, because of the very shallow penetration compared to typical boreholes, the method is particularly susceptible to errors arising from lake bottom perturbations such as annual overturn and sedimentation.

Indirect geochemical methods also exist for estimating subsurface temperatures, based on the solubility of various chemical species in water as a function of temperature. In particular, the silica geothermometer has been used to develop an empirical heat flow estimator (Swanberg \& Morgan 1978).

Thermal conductivity measurements are made in a laboratory setting on 
rock samples taken from the site of the field temperature measurements. The labortory measurement contrasts with in situ techniques that are useful in the soft sediments characteristic of marine (and lake) sites. The most suitable conductivity samples are drawn from the solid cylindrical rock core extracted from the borehole in which temperature measurements were obtained. The number of samples taken is dependent on the variability of the core lithology and on the depth interval at which temperatures were obtained; ideally, at least one sample will be available to represent the depth interval between temperature measurements.

The laboratory measurement is most commonly carried out in an apparatus known as a divided bar (Birch 1950). The measurement is based on a comparison principle in which a known quantity of heat is conducted through two materials - a standard of known conductivity (usually fused silica) and a rock sample of unknown conductivity. The temperature drops across each are proportional to their respective conductivities, and with the one known the other can then be calculated. Samples are water saturated prior to measurement in order to make the conductivity determination in an environment that is as similar to the natural environment as possible. The measurement is also carried out at a temperature appropriate to the in situ temperature of the rock.

In the drilling of some boreholes, particularly for petroleum and water, rock fragments or chips, rather than solid cores, are obtained. These fragments are amenable to conductivity measurements (Sass et al 1971) in the same manner as discs of core, by filling a disc-shaped container with both chips and water and determining the conductivity of the loaded container as if it were a rock disc. Knowing the fraction of the container volume occupied by the rock chips enables the calculation of the intrinsic rock conductivity.

Transient methods of determining thermal conductivity also are utilized. They employ a line source of heat within the body of a sample, with the thermal conductivity emerging from the asymptotic value of the rate of change of temperature with the logarithm of time. The transient method is particularly suited for use in soft sediments, where a heating needle is inserted into the sample. The method is also employed (with some modification) to solid materials with planar surfaces, which sandwich the line source of heat.

The experimental uncertainties in the measurement of temperature gradients and thermal conductivities seldom exceed 5\%. Experimental errors, however, are not the major source of uncertainty in a heat flow determination. The variability of conductivity within a visually homogeneous length of core can easily exceed the measurement error and introduces a sampling uncertainty. Local geological structures, with attendant distributions of conductivity contrasts, can distort the heat flow lines and isothermal surfaces sufficiently to yield local variations in heat flow of $20-30 \%$ about a regional mean. Similarly, slow ground water circulation and the evolution of topography by uplift 
and erosion or subsidence and deposition can have large effects on the nearsurface heat flow distribution. Thus it is the effects of less than adequately known subsurface structure, hydrologic patterns, and geologic, climatic, and geomorphic evolution of a terrane that are the principal uncertainties associated with heat flow determination.

\section{THE CONTINENTAL HEAT FLOW DATA SET}

It has been known from antiquity that the interior of the Earth is a great reservoir of heat. Many references to and measurements of the increase of temperature with depth appear in the scientific literature, dating back at least to Robert Boyle (1671). However, it was not until 1882 that the first determinations of both the geothermal gradient and thermal conductivity were combined by William Thomson (Lord Kelvin) to yield an estimate of the heat flow in Great Britain (British Association 1883). Kelvin utilized both published and personal measurements of temperatures in boreholes and mines throughout Britain to obtain a mean gradient, which when combined with determinations of the thermal conductivity of representative rocks led to a heat flow value of $68 \mathrm{~mW} \mathrm{~m}$.

The motivation for Kelvin's determination of the heat flow was related to his position in the nineteenth century debate over the age of the Earth and Sun. He believed that the Earth was cooling by conduction from a hot primordial condition, and therefore the heat loss from the planet would diminish with time. A measurement of the heat flow would determine how far along in the cooling history the Earth had progressed. Subsequent discoveries have rendered untenable Kelvin's approach to determining the age of the earth. The first nail in the coffin was the discovery of radioactivity in the late nineteenth century, and the quick recognition of its significance as a heat source that replenished to some degree the escaping primordial heat of the Earth. ${ }^{1} \mathrm{~A}$ second difficulty arises from the more recent realization (Tozer 1965, 1972) that temperature-dependent solid-state creep may be a very significant process within the Earth's mantle that leads to heat transfer principally by convection, rather than by conduction as Kelvin had assumed.

A hiatus of interest in geothermal measurements set in following the laying to rest of both Kelvin and his hypothesis, until the late 1930s when Edward Bullard initiated the modern systematic investigtion of heat flow with a series of measurements in South Africa. In North America, Francis Birch recognized early the significance of heat flow to the tectonic and petrologic evolution of

\footnotetext{
${ }^{1}$ It is interesting to note that the conductive cooling of the oceanic lithosphere following its magmatic emplacement at oceanic ridges does yield an age dependence of heat flow of the same form that Kelvin derived for the entire Earth. Indeed the mean age of the oceanic lithosphere is very similar to Kelvin's estimate of the Earth's age.
} 


\section{POLLACK}

the Earth's crust, and established a geothermal laboratory that was for two decades one of the principal centers for geothermal research in the world. Birch's students and research associates, and a generation of scientists subsequently trained by them, now carry on geothermal studies in more than a score of institutions.

In the first review of heat flow measurements, prepared by Birch in 1954, the total number of determinations on the continents was 43 . Subsequently the data set has grown substantially, until in 1981 the number of published continental measurements approaches 3000; a large body of unpublished data exists in the national laboratories of several countries. Significant periodic reviews of the global heat flow data document the dramatic increase in awareness of the significance of the Earth's heat loss, and accordingly in the importance of heat flow measurement (Table 1).

Heat flow measurements have been made in at least modest numbers on all the continents except Antarctica (although a few exist there as well). However, the number and distribution of measurements on the continents remain very uneven (Figure 1). Not surprisingly the greatest concentration of data occurs in the northern continents. Of the total data set, approximately $50 \%$ is from Europe and western USSR, 30\% from North America, 10\% from Asia, and $10 \%$ from Australia, Africa, South America, and Antarctica combined. Of the total area represented by continents, about $30 \%$ has been sampled by heat flow measurements. Significant national reviews of heat flow data include Australia (Sass \& Lachenbruch 1978), the European countries-and western USSR (Cermak \& Rybach 1979), Japan (Uyeda 1972), and the United States (Sass et al 1980). The data set clearly has a geographical bias; it also has more subtle geologic and tectonic biases as well. For example, in the United States roughly $75 \%$ of the heat flow measurements have been made in states from the Rocky Mountains westward because that region exhibits above average heat flow and has been a principal focus in geothermal energy exploration. Because of such biases, simple statisitics, such as the mean or median of all observations, are of limited use; they tend to overestimate significantly the heat flow from the continents as a whole. An areally weighted data set yields improved estimates, but is still hampered by the fact that less than half of the continental area has been sampled with measurements.

Table 1 Numbers of published heat flow measurements

\begin{tabular}{lccl}
\hline \hline Year of compilation & Continental & Oceanic & \multicolumn{1}{c}{ Reference } \\
\hline 1954 & 43 & 20 & Birch (1954a) \\
1965 & 131 & 913 & Lee \& Uyeda (1965) \\
1970 & 597 & 2530 & Lee (1970) \\
1976 & 1699 & 3718 & Jessop et al (1976) \\
1979 & 2808 & 4409 & Chapman \& Pollack (1980) \\
\hline
\end{tabular}




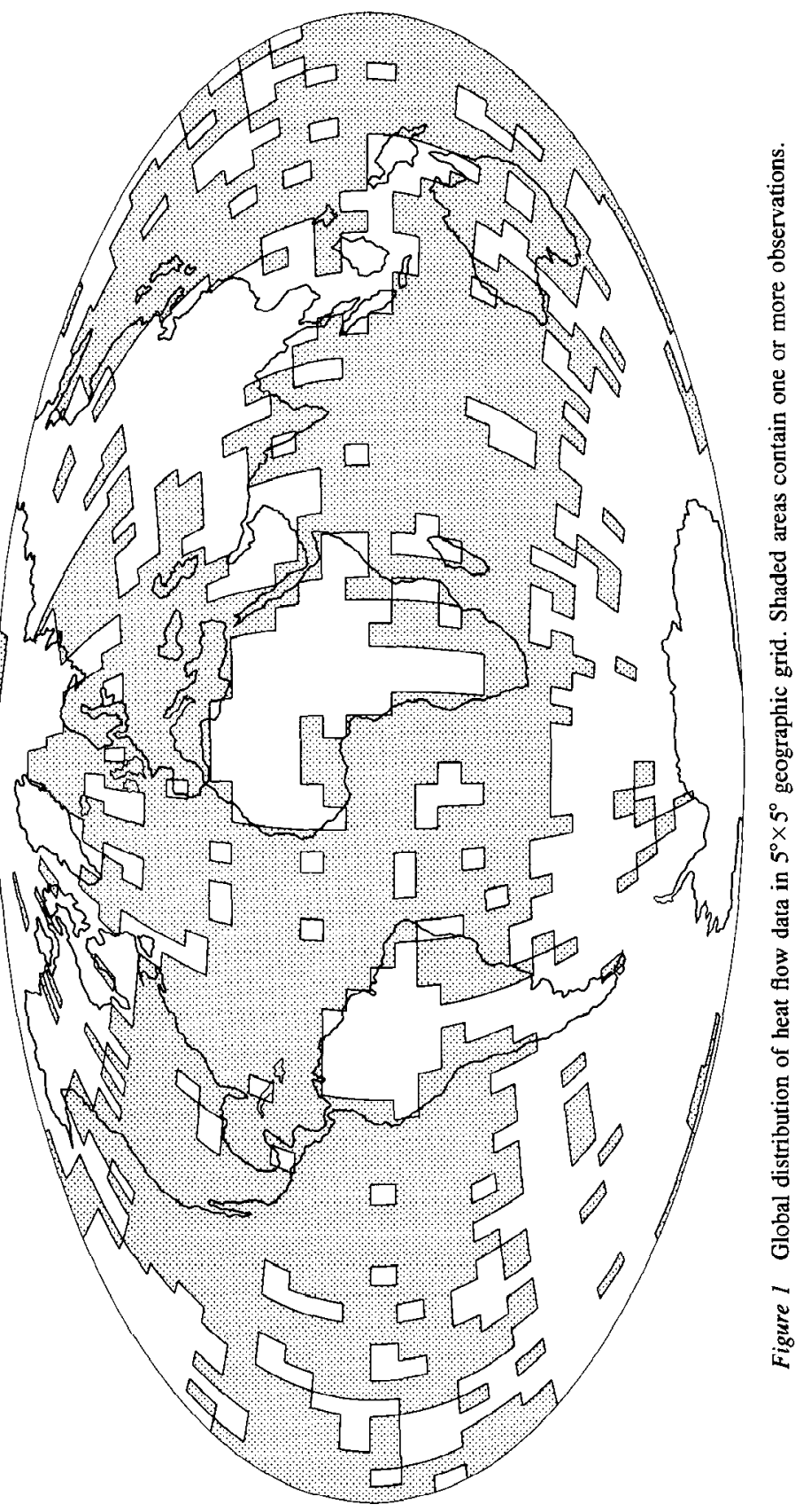


Because temperature gradients are usually determined at depths no greater than a few hundred meters, the possibility exists that long term climatic variations, such as those characterizing the glacial and interglacial intervals of the Pleistocene and Holocene, may have perturbed subsurface temperatures in the first kilometer or so of depth, thus introducing a transient into the heat flow determination (Birch 1948). Inasmuch as the climatic variations in the Pleistocene were not confined to high latitudes but were global, Beck (1977) has argued that there exists the possibility of systematic error within the entire continental heat flow data set. The demonstration of such a bias must come from measurements in very deep boreholes, which would reveal a variation in heat flow with depth; unfortunately very few deep holes have been temperature logged in adequate detail to resolve this question.

Comparable perturbations must also be considered in tectonic terranes undergoing uplift, because the temperature at the surface will diminish with increasing elevation due to the adiabatic lapse rate in the atmosphere, thus introducing a transient into the surface heat flow. A kilometer of uplift over a million years (not uncommon in orogenic belts) would be accompanied by some $5^{\circ} \mathrm{C}$ of surface cooling, clearly similar in magnitude to climatic perturbations over similar time intervals.

Erosion likewise can introduce a transient into the surface heat flow by exposing deeper warmer rocks to surface conditions (Birch 1950, Jaeger 1965). When erosion rates are sufficiently high so as to remove a given thickness of rock in less time than is required for a surface temperature perturbation to propagate to that depth, the erosional transient can be a significant fraction of the observed heat flow.

\section{VARIATION OF HEAT FLOW WITH AGE}

As soon as a small number of heat flow observations from different tectonic settings began to accumulate, it became apparent that there were differences in the thermal characteristics of various tectonic elements. Kraskovski (1961) noted that the heat flux from Precambrian shields generally was less than that from younger terranes. Lee \& Uyeda (1965) assembled 131 continental measurements into broad age groups, which showed the heat flow in Cenozoic volcanic terranes to be, on average, more than twice that from the shields. Polyak \& Smirnov (1968), in a detailed and systematic analysis of 446 measurements, demonstrated a general decrease of heat flow with tectonic age. With increasing numbers of observations, analyses of data subsets for North America (Sclater \& Francheteau 1970) and Europe (Cermak \& Rybach 1979) established separate but similar patterns for those two well-studied continents. Recent analyses of large global data sets (Chapman \& Furlong 1977, 1699 continental observations; Sclater et al 1980, 1411 continental observations) 
differ in detail but confirm the general decrease of heat flow with age (Table 2). As can be seen in both compilations in Table 2, the scatter of the observations is greatest in the youngest age group, probably due in part to the effects of hydrothermal circulation driven by the steep temperature gradients in young terranes (Lachenbruch \& Sass 1977, Blackwell 1978).

In all such analyses, the definition of age is important; usually it is the age of the last tectonothermal mobilization of the terrane in which the measurement is made. Measurements in undeformed platform sediments carry the age of stabilization of the platform basement, measurements in igneous bodies carry the radiometric age of the intrustion or flow, a fold belt carries the youngest age of deformation, and a metamorphic terrane carries the age of the latest thermal metamorphic episode. Obviously the assignment of age is somewhat subjective, particularly in partially or weakly remobilized terranes, and this subjectivity contributes to some of the scatter about the age-group heat flow means. Moreover, there are certain geologic and tectonic settings where the regional heat flow may depart significantly from the appropriate age-group mean. Examples would include the low heat flow of Mesozoic or Cenozoic continental margins situated above ongoing or recent subduction, as observed by Lachenbruch (1968) in the Sierra Nevada of California, by Blackwell et al (1978) on the western margin of Oregon, and by Henry (1981) in the coastal region of Peru. Another example is the elevated heat flow in Precambrian terranes of Africa undergoing or in a stage antecedent to rifting (Morgan \& Swanberg 1978, Chapman \& Pollack 1977).

Anyone familiar with the heat flow literature can point to other departures from the general pattern of decreasing heat flow with increasing age, and indeed some critics question the existence of this empirical relationship. Critics notwithstanding, I believe the empiricism to be well established, although why such a generality should emerge from such a variety of geologic and

Table 2 Variation of heat flow with age of most recent tectonothermal event

\begin{tabular}{|c|c|c|c|c|c|c|c|}
\hline \multicolumn{4}{|c|}{ Chapman \& Furlong (1977) } & \multicolumn{4}{|c|}{ Sclater et al (1980) } \\
\hline Age group & $\begin{array}{c}\text { Mean } \\
\text { heat } \\
\text { flow } \\
\left(\mathrm{mW} \mathrm{m}^{-2}\right)\end{array}$ & $\begin{array}{l}\text { Standard } \\
\text { deviation }\end{array}$ & $\mathbf{N}$ & $\begin{array}{l}\text { Age group } \\
\text { (m.y.) }\end{array}$ & $\begin{array}{c}\text { Mean } \\
\text { heat } \\
\text { flow } \\
\left(\mathrm{mW} \mathrm{m}^{-2}\right)\end{array}$ & $\begin{array}{r}\text { Standard } \\
\text { deviation }\end{array}$ & $\mathbf{N}$ \\
\hline Archean & 41 & 11 & 136 & \multirow{3}{*}{$\begin{array}{r}>1700 \\
800-1700\end{array}$} & \multirow{3}{*}{$\begin{array}{l}46 \\
50\end{array}$} & \multirow{3}{*}{$\begin{array}{l}16 \\
10\end{array}$} & \multirow{3}{*}{$\begin{array}{l}37 \\
138\end{array}$} \\
\hline Early Proterozoic & 51 & 21 & 78 & & & & \\
\hline Late Proterozoic & 54 & 20 & 265 & & & & \\
\hline Early Paleozoic & 52 & 17 & 88 & \multirow[t]{2}{*}{$250-800$} & \multirow[t]{2}{*}{63} & \multirow[t]{2}{*}{21} & \multirow[t]{2}{*}{500} \\
\hline Late Paleozoic & 61 & 18 & 514 & & & & \\
\hline Mesozoic & 73 & 29 & 85 & \multirow{3}{*}{$0-250$} & \multirow{3}{*}{76} & \multirow[b]{2}{*}{53} & \multirow[b]{2}{*}{398} \\
\hline Cenozoic & 71 & 37 & 587 & & & & \\
\hline & & Total & 1753 & & & Total & 1411 \\
\hline
\end{tabular}




\section{$468 \quad$ POLLACK}

tectonic circumstances is not well understood. Specific tectonic and thermal models have been proposed for an extensional setting, such as the Basin and Range province of western North America (Lachenbruch 1978), and for magmatic accretion to the crust in convergence zones (Wells 1980). A generalized thermal model (Vitorello \& Pollack 1980) linked directly to the observed variation of heat flow with age is discussed in more detail below.

One of the uses for the heat flow-age relationship is the estimation of heat flow in unsurveyed areas on the basis of the tectonothermal age of the terrane. Chapman \& Pollack (1975) supplemented the existing heat flow observations with such estimates to produce a global data set and the first global heat flow map. A similar analysis by Sclater et al (1980), incorporating additional data and with adjustments for the heat lost to ocean water circulating through the young oceanic crust, has established a mean heat flow of $57 \mathrm{~mW} \mathrm{~m}^{-2}$ for the continents (including marine shelves) and $99 \mathrm{~mW} \mathrm{~m}^{-2}$ for the oceans; the global weighted average is $82 \mathrm{~mW} \mathrm{~m}$. The notion, firmly rooted in the literature for more than two decades, that oceanic and continental heat flow are approximately equal, is no longer tenable.

\section{RADIOGENIC HEAT}

Since the discovery of radioactivity by Becquerel in 1896 and the identification of radioisotopes in rocks in the early part of this century, it has been recognized that the energy liberated by radioactive decay ultimately is dissipated as heat and comprises a significant component of the heat flow from the continents. The principal heat producing isotopes are ${ }^{232} \mathrm{Th},{ }^{238} \mathrm{U},{ }^{40} \mathrm{~K}$, and ${ }^{235} \mathrm{U}$ with respective half-lives of $14.0,4.47,1.25$, and .70 billion years. Other radioactive isotopes do not presently contribute significantly to terrestrial heat, either because their decay chains are not sufficiently energetic, their abundances are insignificant, or their half-lives are too short. However, certain short-lived isotopes, such as ${ }^{26} \mathrm{Al}$ or ${ }^{129} \mathrm{I}$, may have been substantial contributors to the thermal budget in the early history of the Earth.

Accordingly, an important adjunct to heat flow investigations has been the measurement of isotopic abundances in rocks and the determination of the heat production therefrom (Birch 1954b, Adams \& Gasparini 1970). The concentrations of uranium and thorium in crustal rocks are generally in trace amounts measured in parts per million, while potassium is considerably more abundant, with concentrations of a few percent, of which a small but well-known fraction is ${ }^{40} \mathrm{~K}$. The abundances of those isotopes are commonly obtained using a multichannel gamma ray spectrometer, which separates and counts gamma ray emissions on the basis of energy. Certain steps in the decay pattern of each isotope involve gamma radiation with characteristic energies and thus are indicative of the individual isotopic abundances in the sample.

The abundances of heat producing isotopes in rocks are highly variable, as 
can be seen in Table 3. There is almost an order of magnitude decrease in concentrations of $U, T h$, and $K$ from granites to gabbros, and another very substantial decrease from mafic to ultramafic rocks. However, in all these rock types the ratios of $T h / U$ and $K / U$ are much less variable than the actual abundances. In a recent analysis, Taylor \& McLennan (1981) estimate 3.8 and $1.0 \times 10^{4}$ as characteristic values for $\mathrm{Th} / \mathrm{U}$ and $\mathrm{K} / \mathrm{U}$, respectively, in the crust. In terms of heat production within the crust and upper mantle, the data of Table 3 imply a marked upward concentration of the Earth's heat-producing isotopes, particularly in the continents. The processes by which this segregation has occurred are not well understood, but clearly it is closely associated with the magmatic and metamorphic evolution of the continents as a whole. These isotopes represent elements with relatively large ionic radii in comparison to silicon, aluminum, magnesium, calcium, iron, and oxygen, which comprise the bulk of the Earth's mantle as oxide minerals. The larger ions fit less readily into the denser crystal lattices of the mantle oxides; in magmatic and metamorphic events they are more easily mobilized and tend to accompany the magmatic derivatives and metasomatic volatiles upward where they are incorporated into the more open crystal structure of the crust.

The contribution to the surface heat flow of the continents by crustal radioactivity and its attendant heat production is substantial. Indeed, a crust comprised completely of granodiorite could generate the entire average continental heat flow, with no flux from the mantle required. The continental crust, of course, is not granodiorite throughout, although the upper several kilometers in many areas may be approximately that composition. The middle and lower crust is thought to comprise principally metamorphic amphibolites and granulites with lesser heat production. Petrologically and geophysically realistic models of the heat source distribution (Smithson \& Decker 1974, Smithson \& Brown 1977, Allis 1979) indicate that about $25 \mathrm{~mW} \mathrm{~m}^{-2}$ - some $40 \%$ of the average continental heat flow-arises radiogenically within the continental crust. When weighted by the area of the continents, this crustal radiogenic heat represents $12 \%$ of the global heat loss.

Table 3 Heat production of common rocks (after Rybach 1973, 1976) and of the continental crust (after Taylor \& McLennan 1981)

\begin{tabular}{lllllccc}
\hline \hline & $\mathrm{U}$ & $\mathrm{Th}$ & $\mathrm{K}$ & & & $\begin{array}{c}\text { Heat } \\
\text { Density } \\
\left.(\mathrm{g} \mathrm{cm})^{-3}\right)\end{array}$ & $\begin{array}{c}\text { Hroduction } \\
10^{-6} \mathrm{~W} \mathrm{~m}^{-3}\end{array}$ \\
\hline Granite/Rhyolite & 3.9 & 16.0 & 3.6 & 4.1 & $0.9 \times 10^{4}$ & 2.67 & 2.5 \\
Granodiorite/Dacite & 2.3 & 9.0 & 2.6 & 3.9 & $1.1 \times 10^{4}$ & 2.72 & 1.5 \\
Diorite/Andesite & 1.7 & 7.0 & 1.1 & 4.1 & $0.7 \times 10^{4}$ & 2.82 & 1.1 \\
Gabbro/Basalt & 0.5 & 1.6 & 0.4 & 3.2 & $0.8 \times 10^{4}$ & 2.98 & 0.3 \\
Peridotite & 0.02 & 0.06 & 0.006 & 3.0 & $0.3 \times 10^{4}$ & 3.23 & 0.01 \\
Dunite & 0.003 & $\mathbf{0 . 0 1}$ & $\mathbf{0 . 0 0 0 9}$ & 3.3 & $0.3 \times 10^{4}$ & 3.28 & 0.002 \\
Continental crust & 1.25 & $\mathbf{4 . 8}$ & $\mathbf{1 . 2 5}$ & 3.8 & $1.0 \times 10^{4}$ & - & 0.8 \\
\hline
\end{tabular}


The continental crust also exhibits lateral heterogeneity, probably at all levels. Roy et al (1968) observed that the variability of heat flow in some regions is simply related to the variable heat production of the surface rocks. The empiricism is expressed as $q_{0}=q_{\mathrm{r}}+b A_{0}$, where $q_{0}$ is the surface heatflow, $A_{0}$ is the volumetric heat production of the surface rocks, $q_{\mathrm{r}}$ is the "reduced" heat flow (i.e. the heat flow that would be observed in the absence of any upper crustal heat production), and $b$ is a parameter with dimension of depth that characterizes the vertical distribution of heat sources within the crust. The relationship in effect separates a variable shallow contribution from a uniform deeper contribution to the surface heat flow of an area. Roy et al (1968) define a heat flow province as a geographic area in which the heat flow and heat production are linearly related.

In the years following the initial observation of this linear relationship some seventeen heat flow provinces have been identified; their parameters are tabulated by Vitorello \& Pollack (1980) and their distribution is shown in Figure 2. The provinces range in age from Archean to Cenozoic; some provinces comprise terranes of diverse ages. The relationship is sometimes obscured in young terranes by the effect of hydrothermal circulation, but careful winnowing of the observations can demonstrate its existence (Blackwell 1978). Each province has a characteristic reduced heat flow and source distribution parameter. From province to province the reduced heat flow varies from about 10 to $70 \mathrm{~mW} \mathrm{~m}^{-2}$, while the source distribution parameter is in the range of 4 to $16 \mathrm{~km}$. In the subsequent discussion, one should keep in perspective the relative state of knowledge of the reduced heat flow. While there are a few thousand direct measurements of surface heat flow, and several hundred suites of rocks for which heat production has been determined, there are less than twenty published estimates of the reduced heat flow derived from joint heat flow-heat production investigations.

Roy et al (1968) interpreted the linear heat flow-heat production relationship with a simple model in which different elements of a heat flow province are represented by discrete areas of equal thickness but each with a different heat production, $A_{0}(x, y)$. The parameter $b$ then represents the present common thickness of the blocks, and $b A_{0}(x, y)$ is the regionally variable upper crustal increment to $q_{\mathrm{r}}$, the regionally uniform reduced heat flow from below. In this model $b$ would decrease with time as erosion removed heat sources from the surface, provided the erosion acted uniformly over the entire surface of the province.

Lachenbruch (1970) presented a thorough analysis and interpretation of the linear heat flow-heat production relationship. He demonstrated that several radiogenic source distributions can satisfy the linear relationship, including an exponential source distribution of the form $A_{0} \exp (-z / b)$. In such a model the variability of the surface heat production arises from erosion to various 


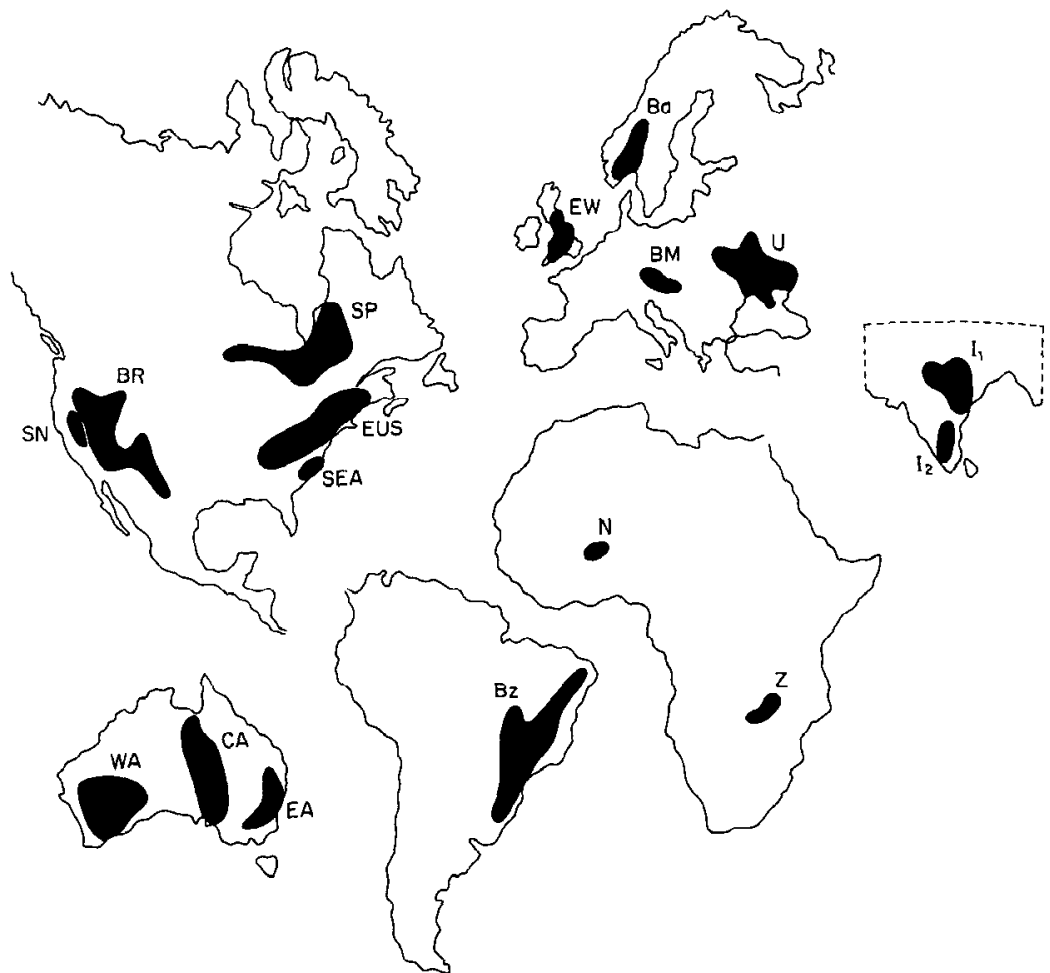

Figure 2 Geographic distribution of seventeen heat flow provinces where the relationship between measured heat flow and radiogenic heat production from near-surface rocks has been empirically determined: SN denotes Sierra Nevada; SP, Superior Province; EUS, eastern United States; SEA, southeastern Appalachians; Bz, Brazilian coastal shield; Ba, Baltic shield; EW, England and Wales; BM, Bohemian Massif; U, Ukrainian shield; N, Niger; Z, Zambia; $I_{1}$, late Proterozoic province of India; $I_{2}$, Archean shield of India; WA, western Australia; $C A$, central Australia; EA, eastern Australia; and BR, Basin and Range (Reprinted by permission from I. Vitorello and H. N. Pollack, J. Geophys. Res. 85:(B2):983-95. Copyright (C) 1980 by the American Geophysical Union).

depths in the source distribution, while $b$ (the logarithmic decrement or vertical scale length of the distribution) remains unchanged during the erosional evolution of the province.

Another empiricism first proposed by Pollack \& Chapman (1977) and later elaborated by Vitorello \& Pollack (1980) relates the reduced heat flow of a province to the average heat flow therein via a simple proportionality: $q_{\mathrm{r}}=0.6 q$. Conceptually the empiricism is reasonable; it asserts that in provinces of higher average heat flow, the reduced heat flow is also proportionally higher, i.e. a greater heat flux at the surface is in part due to an increased flux from the mantle. The complement of this relationship is that crustal radiogenic 
heat comprises about 0.4 of the mean heat flow of a province, with the implication that higher heat flow provinces display proportionally greater crustal radioisotopic enrichment. This implies a linkage between thermal mobilization of a magmatic or metamorphic province, accompanied by a higher reduced heat flow, and the concomitant radioisotopic enrichment of the upper crust.

It is widely accepted that heat-producing isotopes are redistributed upward by magmatic and metamorphic processes, but the details of the fractionation, transfer, and stabilization at upper crustal levels remain less clear (Lambert \& Heier 1967, Albarede 1975, Heier 1978, Jaupart et al 1981). While U, Th, and $\mathbf{K}$ are geochemically coherent in magmatic fractionation, they diverge somewhat during crystallization and have rather different recycling characteristics in the presence of meteoric or juvenile thermal waters or other volatiles. Subsequent to the magmatic and/or metamorphic peak, the mobilized terrane undergoes conductive cooling, accompanied by a decrease in the reduced heat flow with time. The corresponding decrease in the crustal radiogenic heat, which preserves the empirical proportionality, apparently is accomplished by erosion and removal of radioelements from surface rocks.

The surface heat flow, surface heat production, source distribution parameter, and reduced heat flow provide strong constraints on temperatures in the continental crust. Crustal temperatures are strongly dependent on the reduced heat flow, and thus differences in the thermal structure between heat flow provinces arise principally from variations in the subcrustal flux. Temperature versus depth curves ("geotherms") characterizing the thermal regime of the crust have been calculated for a variety of heat flow settings by Lachenbruch \& Sass (1977). Pollack \& Chapman (1977) present a general family of geotherms, each corresponding to a different surface heat flow and extended to upper mantle depths.

\section{THE THERMAL EVOLUTION OF CONTINENTS}

The heat lost at the surface of the Earth is the principal observational constraint on models of the internal dynamics and thermal evolution of the planet. As noted in the introduction, the greater part-nearly three fourths of the total-is exhausted through the creation and subsequent cooling of new oceanic lithosphere at oceanic ridges. The plates of oceanic lithosphere serve as the cooling fins of the Earth's heat engine. The heat flow from the continents, while representing only sligthly more than one fourth of the planetary heat loss, is closely associated with the petrology and trace element chemistry of the continental crust, and therefore must be an important component of any model of the thermal, petrologic, and tectonic evolution of the continents.

The aspect of continental heat flow most central to evolutionary models has 
been the age dependence. Models divide roughly into two types. The first and more common type (Crough \& Thompson 1976, Vitorello \& Pollack 1980) interprets the decline of heat flow with age in terms of deep-seated thermal and petrologic processes intimately associated with the development and evolution of the continental lithosphere. The second type of model (England \& Richardson 1980) interprets the age dependence of the heat flow principally in terms of processes within and erosion of the continental crust, with little requirement for the involvement of the continental upper mantle and with little implication for the thermal evolution of the subcrustal lithosphere.

England \& Richardson place considerable weight on the effects of deep erosion on the heat flow in continental mobile belts, emphasizing the temporary augmentation of the surface heat flow by the progressive uncovering of deeper and warmer crustal rocks. They argue that, in comparison to the typical crustal thickness of shields and stable platforms, the excessive crustal thicknesses observed in Cenozoic convergence zones involving continents represents an unconsummated erosion that will eventually remove $20-40 \mathrm{~km}$ of the crust. Such erosion on a suitable time scale can account for the observed decay of surface heat flow without any need of augmentation by magmatic activity or deeper heat flow.

The England \& Richardson model, while perhaps appropriate to the Alps, is lacking in generality. The higher heat flow of Cenozoic terranes is observed not only in continental convergence zones, but also in several other tectonic settings, such as the Rhinegraben, Massif Central and Pannonian Basin of Europe, and the Basin and Range province of western North America, for which the deep erosional arguments are less persuasive. None of these areas exhibit erosion to deep crustal levels and all exhibit relatively thin crust. Nonmagmatic thickening of continental crust may perhaps be a tenable process in a continent-continent collision, as in the Alps or Himalayas, but it is less credible as an explanation of the Andean root, where the subduction is oceanic and the thick crustal root is centered on the zone of Pleistocene and Holocene volcanism. Indeed, the evolution of the entire western Cordillera of both North and South America is marked by extensive magmatism over long periods of time. While nonmagmatic processes may occasionally provide a mode of crustal thickening, it seems unlikely that this has been the characteristic mode of the Mesozoic and Cenozoic.

The contrasting model presented by Vitorello \& Pollack interprets the age dependence of continental heat flow in terms of three components (see Figure 3): (I) a radiogenic component arising from the zone of radioelement enrichment within the crust, (II) a contribution derived from the cooling of a thermal perturbation associated with the tectonothermal mobilization that defines the "thermal age" of the crust, and (III) a background heat flow, probably of deep origin, with no significant time variation and contributing 


\section{$474 \quad$ POLLACK}

equally to terranes of all ages. All three components are approximately equal in young terranes, while in ancient terranes only the crustal radiogenic and background components remain, the former reduced by half by erosion into the zone of crustal heat sources. Because a significant part of the variation of

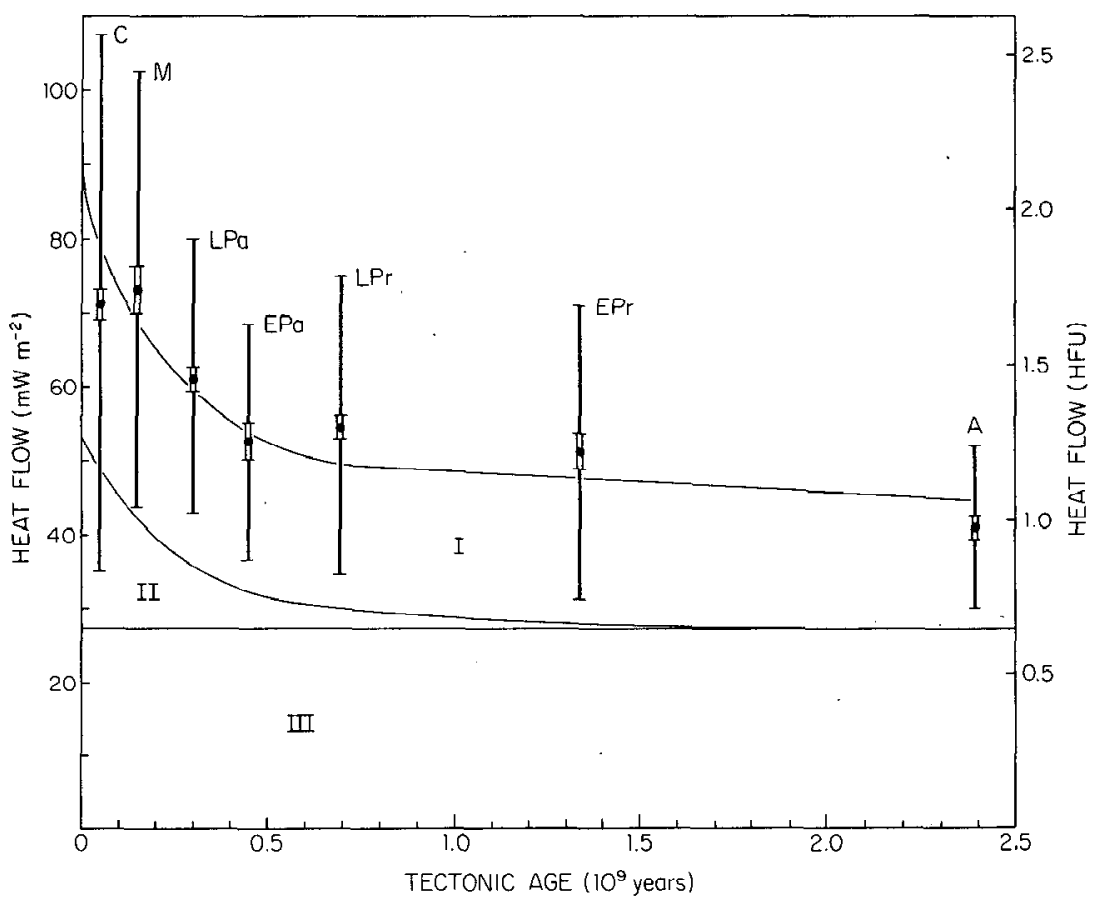

Figure 3 Decrease of continental heat flow with age and its three principal components; component $I$ is radiogenic heat from the crust, component II is heat from the transient thermal perturbation associated with tectonogenesis, and component III is the background heat flow from deeper sources (after Vitorello \& Pollack 1980). The data points are from Chapman \& Furlong (1977). C denotes Cenozoic; M, Mesozoic; LPa, late Paleozoic; EPa, early Paleozoic; LPr, late Proterozoic; EPr, early Proterozoic; and A, Archean. Points are plotted at the mean age of the respective age ranges. Double bars represent the standard error of the mean; single bars the standard deviation. The upper curve corresponds to a visually fitted curve through the data points; the middle curve corresponds to $60 \%$ of the upper curve; the lower curve represents the background heat flow from deeper sources. (Reprinted by permission from I. Vitorello and H. N. Pollack, J. Geophys. Res. 85(B2):983-95. Copyright (C) 1980 by the American Geophysical Union.) 
heat flow with age in this model arises from the decay of the thermal perturbation, the pace and extent of the requisite erosion is much less than in England \& Richardson's model, and therefore the heat flow transient introduced by the erosion is insignificant.

In contrast to the oceanic thermal regime, where the cooling of lithosphere from an initial high temperature yields a simple (age) ${ }^{-1 / 2}$ dependence for the heat flow, the continental flux has a longer and more complex age dependence governed by the time scales of two different processes: crustal erosion and lithospheric cooling. In the Vitorello \& Pollack model, the time scale of the erosion is fixed by the requirement that the crustal radiogenic heat must diminish in proportion to the surface heat flow; the cooling time scale is thereby fixed, as the cooling of the thermal perturbation must provide the remaining time dependence of the heat flow.

The cooling and background components of the Vitorello \& Pollack model together comprise a "reduced" heat flow that diminishes with time, and this decay can be compared to the observed variation of reduced heat flowwith age. Sclater et al (1980) compile and display such data and note that the reduced heat flow apparently decays in $200-400$ m.y. to a "background" level, somewhat faster than the 300-500 m.y. decay of reduced" heat flow of the Vitorello \& Pollack model.

Vitorello \& Pollack present models of the magnitude and configuration of the thermal perturbation that in cooling will yield component II of the heat flow. A perturbed zone some $300-500 \mathrm{~km}$ thick, with a maximum temperature disturbance of $750-850^{\circ} \mathrm{C}$ occurring at depths of $80-100 \mathrm{~km}$, provides a good fit to component II (see Figure 4). The inferred depth extent of the perturbed zone is of major significance; it implies that the conducting boundary layer beneath the shields and stable platforms of the continents is some 2-3 times thicker than that beneath oceans, and that it has remained as an entity at least over the time interval since the last major tectonic/magmatic event within it. Even if the thermal perturbation decayed more rapidly, as suggested by the age dependence of the reduced heat flow, the requirement would still exist for a relatively thick conductive boundary layer beneath the stable continental nuclei.

The acquisition of this long-term stability is a complex process intimately linked to the petrological development of the continents. Three types of stability characterize the cratonic lithosphere: thermal, mechanical, and buoyant. Substantial devolatilization of the upper mantle during metamorphic and magmatic events imparts to the lithosphere a stability against later remelting by elevating the solidus to a more refractory state and depressing the eventual equilibrium geotherm by redistributing the heat-producing isotopes upward. Mechanical stability, manifest as a resistance to deformation and dismemberment, is acquired concomitantly with thermal stability; it derives from the 

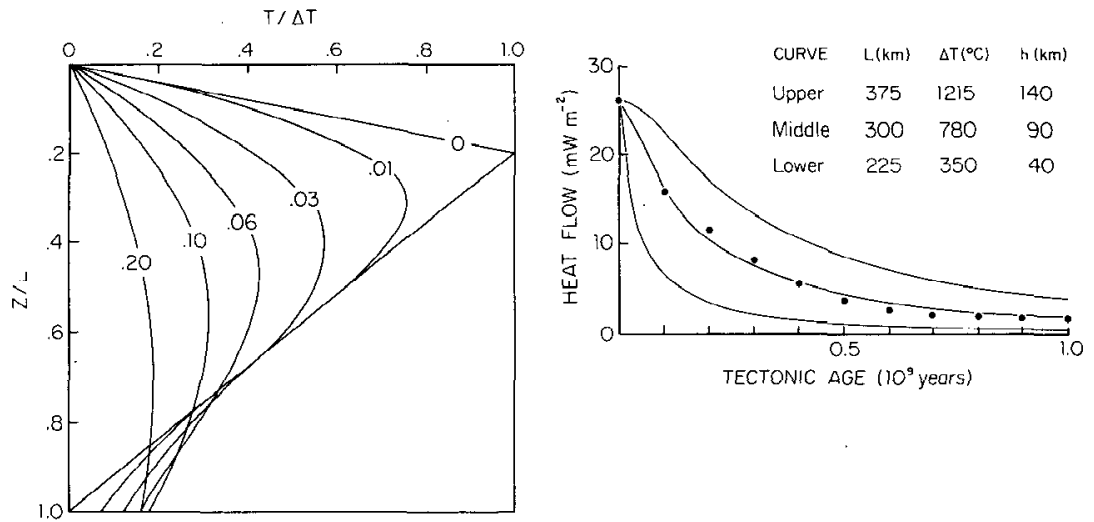

Figure 4 (left) Typical temperature versus depth curves for the cooling of a thermal perturbation within a lithosphere of thickness $L$; the maximum temperature disturbance occurs at a variable depth $h$. Cooling curves are shown for several values of the dimensionless time $k t / L^{2}$, where $t$ is the time since cooling began and $k$ is the thermal diffusivity. (right) The decay of the surface heat flow from the thermal perturbation shown above. The three curves are obtained by varying the layer thickness $L$, the maximum temperature disturbance $T$, and the depth $h$ at which the maximum occurs. Circles are points taken at $100 \mathrm{~m} . \mathrm{y}$. intervals from the curve representing component II in Figure 3 (after Vitorello \& Pollack 1980).

strong dependence of strength and viscosity on both temperature and volatile content. Buoyant stability (the resistance of continental lithosphere to later subduction) is acquired by differentiation during partial melting. Both melt product and residuum may be less dense than the parent mantle, leading to upward migration of the melt in penetrative magmatism followed by an underplate of the refractory residuum. The most complete development of the geophysical and petrological aspects of this thermal, chemical, and mechanical boundary layer can be found in a series of papers by Jordan (1975, 1978, 1981).

Lithospheric stability, therefore, is an acquired property, the result of a thermal and magmatic history that includes an equilibration period on the order of a few hundred million years following a tectonothermal event. During the equilibration period, the affected lithosphere is in a weakened state and is vulnerable to recurrent tectonism and magmatism. In this context it seems not extraordinary that the Atlantic Ocean opened almost exclusively along Paleozoic or latest Precambrian orogenic belts, several of which were at the time of opening recent sutures welding components of Pangea together. Similarly, the occurrences of Cenozoic volcanism in Africa are confined almost exclusively to the Pan-African terranes (Thorpe \& Smith 1974), last remobilized in late Precambrian and early Paleozoic. Because the characteristic time for thermal equilibration (300-500 m.y.) exceeds the characteristic time of major reorganizations of the global plate system (100-200 m.y.), there will be zones of 
lingering weakness within the lithosphere vulnerable to the redistribution of intraplate stress accompanying plate reorganization. Thus it is not surprising to find that persistent zones of weakness and tectonic reactivation of previously mobilized terranes are common geologic phenomena.

If a terrane safely passes through the period of peril and reaches a stable cratonic condition, it is considerably more difficult to remobilize; to do so the processes leading to stabilization must be reversed. A thick, stiff refractory lithosphere can be thinned and weakened by a reinfusion of heat and volatiles from below, a thermal and metasomatic process for which increasing evidence is accumulating (Lloyd \& Bailey 1975, Boettcher et al 1979, Menzies \& Murthy 1980). It seems unlikely, however, that the continental buoyancy can be easily altered or reversed.

Gass et al (1978) and Pollack et al (1981) discuss the parameters that determine whether sublithospheric thermal disturbances penetrate the lithosphere and reach the surface as mid-plate magmatism. They quantitatively examine the interrelationship of plate thickness and velocity, and conclude that thick lithosphere moving rapidly over sublithospheric thermal perturbations is less vulnerable to penetrative magmatism than are thin slowmoving plates. Evidence for this relationship can be seen by the nearly complete absence of Cenozoic volcanism on the thick continental cratons $(>1000$ m.y. age). Because of the durability of the cratons, lithospheric perturbations may not develop fully to the stage of widespread surface volcanism. Crough (1981) assembles geologic evidence of a hot-spot track across eastern North America, more subtle in character than the obvious Hawaiian-Emperor volcanic track across the Pacific. Perturbations of sufficient magnitude and longevity may of course penetrate to the continental surface and leave volcanic tracks; the Snake River volcanic plain culminating at the Yellowstone rhyolite pile is perhaps the clearest modern example. The major Mesozoic flood basalts in the Parana and Karroo Basins and on the Deccan Plateau likely developed above major hot spots of their day.

What can be said of the heat flow earlier in geologic history? Clearly the radiogenic heat production of past times was greater because of the isotopic decay. If the $\mathrm{K} / \mathrm{U}$ ratio throughout the Earth is the same as in the crust, then the heat production $3000 \mathrm{~m}$.y. ago was some 2.75 times greater than the present (Wasserburg et al 1964). However, it is unlikely that the heat flow over the entire surface was greater by that factor; rather an increased heat loss would probably be concentrated in the ocean basins, where the additional heat can be readily exhausted by an increased rate of production of oceanic lithosphere (Bickle 1978).

The radioisotopes actually locked in the continental crust yielded greater heat in past times, of course, but crustal radiogenic heat comprises less than half of the continental heat flow. Moreover, because the increase in heat flow 
occurred principally in the higher levels of the crust, the increment to lower crustal and upper mantle temperatures was not great. The oft-repeated notion that temperature gradients through the Archean protocontinents were substantially higher than present-day gradients is probably untrue. Careful application of metamorphic geothermometry and geobarometry indicates that the range of crustal conditions inferred for Archean terranes are represented in present-day tectonic settings. In particular the conditions for high-grade metamorphism of the lower continental crust exist in the modern Basin and Range province of western North America (Lachenbruch \& Sass 1977).

\section{CONCLUDING REMARKS}

The widespread measurement of terrestrial heat flow has been an endeavor essentially of the last two decades, and is still far from complete in terms of global coverage. However, the recognition of its variability in different settings, both oceanic and continental, has forged an undeniable link between the loss of the Earth's internal heat and tectonic processes within and at the surface of the Earth. On the continents in particular, these processes are intimately associated with the petrological evolution of the continental lithosphere, and with the establishment of those very properties that make the continents stand out: their low density and long-term durability. If the inadequacies of past interpretations from both geophysicists and petrologists can be attributed to an attempt to isolate thermal, rheologic, and petrologic parameters from each other as uncoupled independent variables, then the promise of the future lies in the recognition of the inseparability of these aspects of continental evolution and in the integration of them into a geological equivalent of the "grand unification" theories of physics.

\section{ACKNOWLEDGMENTS}

I am grateful to Francis Birch for stimulating my interest in geothermal studies, and to my late colleague James $T$. Wilson for his encouragement and support over two decades. It is also a pleasure to acknowledge my collaborations with David Chapman, Icaro Vitorello, and Steven Henry; together we have taken the Earth's temperature in many places, and tried to decide whether the patient was feverish or had a chill. The US National Science Foundation has supported geothermal research at the University of Michigan through Grants GA-36360, DES75-17065, EAR78-09131, and INT80-16941.

\section{Literature Cited}

Adams, J. A. S., Gasparini, P. 1970. Gammaray Spectrometry of Rocks. New York: Elsevier. $295 \mathrm{pp}$.

Albarede, F. 1975. The heat flow/heat gener- ation relationship: an interaction mode of fluids with cooling intrusions. Earth Planet. Sci. Lett. 27:73-78

Allis, R. G. 1979. A heat production model for 
the stable continental crust. Tectonophysics 57:151-65

Beck, A. E. 1965. Techniques of measuring heat flow on land. In Terrestrial Heat Flow, ed. W. H. K. Lee, Geophys. Monogr. 8:24-57. Washington DC: Am. Geophys. Union. 276 pp.

Beck, A. E. 1977. Climatically perturbed temperature gradients and their effect on regional and continental heat flow means. Tectonophysics 41:17-39

Bickle, M. J. 1978. Heat loss from the Earth: a constraint on Archean tectonics from the relation between geothermal gradients and the rate of plate production. Earth Planet. Sci. Lett. 40:301-15

Birch, F. 1948. The effects of Pleistocene climatic variations upon geothermal gradients. Am. J. Sci. 246:729-60

Birch, F. 1950. Flow of heat in the Front Range, Colorado. Bull. Geol. Soc. Am. 61:567-630

Birch, F. 1954a. The present state of geothermal investigations. Geophysics 9:645-59

Birch, F. 1954b. Heat from radioactivity. In Nuclear Geology, ed. H. Faul, pp. 148-75. New York: Wiley.

Blackwell, D. D. 1978. Heat flow and energy loss in the western United States. In Cenozoic Tectonics and Regional Geophysics of the Western Cordillera, ed. R. B. Smith, G. P. Eaton, Geol. Soc. Am. Mem. 152:175-208

Blackwell, D. D., Hull, D. A., Bowen, R. R. 1978. Heat flow in Oregon. Oregon Dep. Geol. Min. Ind. Spec. Pap. 4. 42 pp.

Blackwell, D. D., Steele, J. L., Brott, C. A. 1980. The terrain effect on terrestrial heat flow. J. Geophys. Res. 85:4757-72

Boettcher, A. L., O'Neil, J. R., Windom, K. E., Stewart, D. C., Wilshire, H. G. 1979. Metasomatism of the upper mantle and the genesis of kimberlites and alkali basalt. In The Mantle Sample: Inclusions in Kimberlites and Other Volcanics, ed. F. R. Boyd, H. D. A. Meyer, pp. 173-83. Washington D.C: Am. Geophys. Union. 423 pp.

Boyle, R. 1671. Of the temperature of the subterraneal regions as to heat and cold. In Robert Boyle, The Works 1966, ed. T. Birch. Hildesheim: G. Ohlms

British Association. 1883. Rep. 52nd Meet., pp. 72-90. London: John Murray

Cermak, V., Rybach, L. 1979. Terrestrial Heat Flow in Europe. New York: Springer. $362 \mathrm{pp}$.

Chapman, D. S., Furlong, K. 1977. Continental heat flow-age relationships. EOS, Trans. Am. Geophys. Union 58:1240

Chapman, D. S., Pollack, H. N. 1975. Global heat flow: a new look. Earth Planet. Sci. Lett. 28:23-32

Chapman, D. S., Pollack, H. N. 1977. Heat flow and heat production in Zambia: evi- dence for lithospheric thinning in central Africa. Tectonophysics 41:79-100

Chapman, D. S., Pollack, H. N. 1980. Global heat flow: sperical harmonic representation. EOS, Trans. Am. Geophys. Union 61:383

Crough, S. T. 1981. Mesozoic hotspot epeirogeny in eastem North America. Geology 9:2-6

Crough, S. T., Thompson, G. A. 1976. Thermal model of continental lithosphere. $J$. Geophys. Res. 81:4857-62

Davies, G. F. 1980. Review of oceanic and global heat flow estimates. Rev. Geophys. Space Phys. 18:718-22

Degens, E. T., Von Herzen, R. P., Wong, H. 1971. Lake Tanganyika-water chemistry, sediments, geological structure. Naturwissenschaften 58:229-40

England, P. C., Richardson, S. 1980. Erosion and the age-dependence of continental heat flow. Geophys. J. R. Astron. Soc. 62: 421-38

Gass, I. G., Chapman, D. S., Pollack, H. N. Thorpe, R. S. 1978. Geological and geophysical parameters of mid-plate volcanism. Philos. Trans. R. Soc. London Ser. A 288:581-97

Heier, K. S. 1978. The distribution and redistribution of heat-producing elements in the continents. Philos. Trans. $R$. Soc. London Ser. A. 288:393-400

Henry, S. G. 1981. Terrestrial heat flow overlying the Andean subduction zone. $\mathrm{PhD}$ thesis. Univ. Mich., Ann Arbor. 207 pp.

Jaeger, J. C. 1965. Application of the theory of heat conduction to geothermal measurements. In Terrestrial Heat Flow, ed. W. H. K. Lee, Geophys. Monogr. 8:7-23. Washington, D.C: Am. Geophys. Union

Jaupart, C.,. Sclater, J. G., Simmons, G. 1981. Heat flow studies: constraints on the distribution of uranium, thorium and potassium in the continental crust. Earth Planet. Sci. Lett. 52:328-44

Jessop, A. M., Hobart, M. A., Sclater, J. G. 1976. The world heat flow data collection1975. Geothermal Ser. 5, Energy Mines Resour., Earth Phys. Branch, Ottawa

Jordan, T. H. 1975. The continental tectosphere. Rev. Geophys. Space Phys. 13: $1-12$

Jordan, T. H. 1978. Composition and development of the continental tectosphere. $\mathrm{Na}$ ture 274:544-48

Jordan, T. H. 1981. Continents as a chemical boundary layer. Philos. Trans. R. Soc. London Ser. A 301:359-73

Kraskovski, S. A. 1961. Thermal heat in shields. Izv. Akad. Nauk SSSR, ser. geofiz. 3:274-80

Lachenbruch, A. H. 1968. Preliminary geothermal model of the Sierra Nevada. $J$. Geo. phys. Res. 73:6977-90

Lachenbruch, A. H. 1970. Crustal temperature 
and heat production: implication of the linear heat flow relation. J. Geophys. Res. 75:3291-3300

Lachenbruch, A. H. 1978. Models of an extending lithosphere and heat flow in the Basin and Range province. In Cenozoic Tectonics and Regional Geophysics of the Western Cordillera, ed. R. B. Smith, G. P. Eaton, Geol. Soc. Am. Mem. 152:209-50

Lachenbruch, A. H., Sass, J. H. 1977. Heatflow in the United States and the thermal regime of the crust. In The Earth's Crust, ed. J. G. Heacock, Geophys. Monogr. 20:626-75. Washington D.C: Am. Geophys. Union

Lambert, I. B. , Heier, K. S. 1967. The vertical distribution of uranium, thorium and potassium in the continental crust. Geochim. Cosmochim. Acta 31:377-90

Lee, W. H. K. 1970. On the global variations of terrestrial heat-flow. Phys. Earth. Planet. Inter. 2:332-41

Lee, W. H. K., Uyeda, S. 1965. Review of heat flow data. In Terrestrial Heat Flow, ed. W. H. K. Lee, Geophys. Monogr. 8: 87-100. Washington, D. C: Am. Geophys. Union. $276 \mathrm{pp}$.

Lloyd, F. E., Bailey, D. K. 1975. Light elcment metasomatism of the continental mantle: the evidence and the consequences. Phys. Chem. Earth 9:389-416

Menzies, M., Murthy, V. R. 1980. Enriched mantle: $\mathrm{Nd}$ and $\mathrm{Sr}$ isotopes in diopsides from kimberlite nodules, Nature 283:634-36

Morgan, P., Swanberg, C. A. 1978. Heat flow and the geothermal potential of Egypt. Pure Appl. Geophys. 117:213-26

Pollack, H. N. 1980. The heat flow from the earth: a review. In Mechanisms of Continental Drift and Plate Tectonics, ed. P. A. Davies, S. K. Runcorn, pp. 183-92. London: Academic. 364 pp.

Pollack, H. N., Chapman, D. S. 1977. On the regional variation of heat flow, geotherms, and the thickness of the lithosphere. Tectonophysics 38:279-96

Pollack, H. N., Gass, I. G., Thorpe, R. S., Chapman, D. S. 1981. On the vulnerability of lithospheric plates to mid-plate volcanism: reply to comments by P. R. Vogt. $J$. Geophys. Res. 86:961-66

Polyak, B. G., Smirnov, Y. A. 1968. Relationship between terrestrial heat flow and the tectonics of the continents. Geotectonics 4:205-13

Roy, R. F., Blackwell, D., Birch, F. 1968. Heat generation of plutonic rocks and continental heat flow provinces. Earth Plantet. Sci. Lett. 5:1-12

Rybach, L. 1973. Warmeproduktionsbestimmungen an Gesteinen der Schweizer Alpen. Beitr. Geol. Schweiz, Geotechn. Ser. 51. Bern: Kummetly \& Frei
Rybach, L. 1976. Die Gesteinsradioaktivitat und ihr Einfluss auf das Temperaturfeld in der Kontinentalen Kruste. J. Geophys. 42: 93-101

Sass, J. H., Blackwell, D. D., Chapman, D. S., Costain, J. K., Decker, E. R., Lawver, L. A., Swanberg, C. A. 1980 . Heat flow from the crust of the United States. In Physical Properties of Rocks and Minerals. ed. Y. S. Touloukian, W. R. Judd, R. F. Roy, Ch. 13. St. Louis: McGraw-Hill

Sass, J. H., Lachenbruch, A. H. 1978. Thermal regime of the Australian continental crust. In The Earth, Its Origin, Structure and Evolution, ed. M. W. McElhinny, pp. 301-51. New York: Academic

Sass, J. H., Lachenbruch, A. H., Munroc, R. J. 1971. Thermal conductivity of rocks from measurements on fragments and its application to heat flow determinations. $J$. Geophys. Res. 76:3391-3401

Sclater, J. G., Francheteau, J. 1970. The implications of terrestrial heat flow observations on current tectonic and geochemical models of the crust and upper mantle of the earth. Geophys. J. R. Astron. Soc. 20: 509-42

Sclater, J. G., Jaupart, C., Galson, D. 1980. The heat flow through oceanic and continental crust and the heat loss from the Earth. Rev. Geophys. Space Phys. 18:269-311

Sclater, J. G., Vacquier, V., Rohrhirsch, J. H. 1970. Terrestrial heat flow measurements on Lake Titicaca, Peru. Earth Planet. Sci. Lett. 8:45-54

Smithson, S. B., Brown, S. K. 1977. A model for the lower continental crust. Earth Planet. Sci. Lett. 35:134-44

Smithson, S. B., Decker, E. R. 1974. A continental crustal model and its geothermal implications. Earth Planet. Sci. Lett. 22: 215-25

Swanberg, C. A., Morgan, P. 1978. The linear relation between temperatures based on the silica content of groundwater and regional heat flow: a new heat flow map of the United States. Pure Appl. Geophys. 117:227-41

Taylor, S. R., McLennan, S. M. 1981. The composition and evolution of the continental crust: rare earth element evidence from sedimentary rocks. Philos. Trans. R. Soc. London Ser. A 301:381-99

Thorpe, R. S., Smith, K. 1974. Distribution of Cenozoic volcanism in Africa. Earth Planet. Sci. Lett. 22:91-95

Tozer, D. C. 1965. Heat transfer and convection currents. Philos. Trans. R. Soc. London Ser. A 258:252-71

Tozer, D. C. 1972. The present thermal state of the terrestrial planets. Phys. Earth Planet. Inter. 6:182-97

Uyeda, S. 1972. Heat flow. In Crust and Upper Mantle of the Japanese Area, ed. S. 
Miyamura, S. Uyeda, pp. 97-105. Earthquake Res. Inst., Univ. Tokyo

Vitorello, I., Pollack, H. N. 1980. On the variation of continental heat flow with age and the thermal evolution of continents. J. Geophys. Res. 85:983-95

Von Herzen, R. P., Vacquier, V. 1967. Terrestrial heat flow in Lake Malawi, Africa. $J$. Geophys. Res. 72:4221-26
Wasserburg, G. J., MacDonald, G. J. F., Hoyle, F., Fowler, W. A. 1964. Relative contributions of uranium, thorium, and potassium to heat production in the Earth. S $\mathrm{Ci}$ ence 143:465-67

Wells, P. R. A. 1980. Thermal models for the magmatic accretion and subsequent metamorphism of continental crust. Earth Planet. Sci. Lett. 46:253-65 


\section{CONTENTS}

Early Days IN UNIVERSITY GeOPhysics, J. Tuzo Wilson

Poleward Heat Transport by THE OCEAN: Observations and

Models, Kirk Bryan

The Geological Context of Human Evolution,

A. K. Behrensmeyer

DYNAMICAL CONSTRAINTS ON THE FORMATION AND EVOLUTION

of Planetary Bodies, Alan W. Harris and William R. Ward

Thirteen Years of DeEP-Sea Drilling, Kenneth J. Hsü

Cordilleran METAMORPHIC CORE COMPLEXES-From Arizona

to Southern Canada, Richard Lee Armstrong

MiD-OCEAN RIDGES: Fine Scale Tectonic, Volcanic and

Hydrothermal Processes Within the Plate Boundary Zone,

Ken C. Macdonald

Pre-Mesozoic Paleomagnetism and Plate Tectonics,

Rob Van der Voo

The Role of Perfectly Mobile Components IN Metamorphism,

Douglas Rumble, III

221

Earthquake Prediction, Ziro Suzuki

InTERIORS OF the Giant Planets, $D$. $J$. Stevenson

257

Halley's Comet, Ray L. Newburn, Jr. and Donald K. Yeomans

The Transport of Contaminants in the GrEat LaKES,

Wilbert Lick

Regoliths on Small Bodies in the Solar System,

Kevin R. Housen and Laurel L. Wilkening

Heat and Mass Circulation in Geothermal Systems,

Ian G. Donaldson

Magma Migration, D. L. Turcotte

The Basin And Range Province: Origin and Tectonic Significance,

Gordon P. Eaton

Phanerozolc Oolitic Ironstones-Geologic Record and Facies

Model, Franklyn B. Van Houten and Deba P. Bhattacharyya

The Heat Flow from the Continents, Henry $N$. Pollack

APPLiCATIONS OF THE ION MiCROPROBE TO GEOCHEMISTRY AND

COSMOCHEMISTRY, N. Shimizu and S. R. Hart

INDEXES

Author Index

Cumulative Index of Contributing Authors, Volumes 6-10

Cumulative Index of Chapter Titles, Volumes 6-10 